\title{
INHIBITORY EFFECTS OF SANGKETAN (ACHYRANTHES ASPERA L.) ROOT EXTRACTS ON
} ARGINASE ACTIVITY

\author{
DIEAH SITI RAHMAWATI, BERNA ELYA*, ARIKADIA NOVIANI \\ Department of Pharmacognosy and Phytochemistry, Faculty of Pharmacy, Universitas Indonesia, Depok, Indonesia. \\ Email: berna.elya@farmasi.ui.ac.id
}

Received: 23 September 2019, Revised and Accepted: 15 December 2019

\section{ABSTRACT}

Objective: Achyranthes aspera, commonly called Sangketan in Indonesian, is a wild plant used as traditional medicine. The roots of Sangketan can be used as a wound healer, which is attributed to the involvement of arginine and its metabolites, nitric oxide, which directly influence the wound healing process. The aim of the present study was to determine the potential of Sangketan root extracts to inhibit arginase activity.

Methods: The roots were extracted using the multistage ultrasound-assisted extraction method using n-hexane, ethyl acetate, and methanol solvents. Each of the extract associated with the three solvents was tested for arginase inhibition activity using a microplate-based colorimetric method, followed by the determination of total phenolic compound and total flavonoid concentrations.

Results: The results of the inhibition test of arginase activity based on n-hexane, ethyl acetate, and methanolic extracts were 9.56, 17.58 , and 29.77\%, respectively, at concentrations of $100 \mu \mathrm{g} / \mathrm{mL}$; the total phenolic compound concentrations were 3.91, 4.83, and 11.18 mg GAE/g of sample, respectively, and the total flavonoid concentrations were $0.29,0.80$, and $0.88 \mathrm{mg} \mathrm{QE} / \mathrm{g}$ of sample, respectively.

Conclusion: According to the results, Sangketan root extracts had low potency with regard to arginase inhibitory activity.

Keywords: Achyranthes aspera, Arginase, Inhibitory effect, Sangketan, Total flavonoid content, Total phenolic content.

(C) 2020 The Authors. Published by Innovare Academic Sciences Pvt Ltd. This is an open access article under the CC BY license (http://creativecommons. org/licenses/by/4. 0/) DOI: http://dx.doi.org/10.22159/ijap.2020.v12s1.FF054

\section{INTRODUCTION}

Sangketan or Achyranthes aspera L. is a plant that has been used widely in Indonesia as medicine. Conventionally, the roots of Sangketan were used to heal wounds. Numerous studies have also reported that Sangketan has diuretic, antiobesity, antibacterial, antioxidant, wound healing, and immunomodulatory properties $[1,2]$. The plant tissues contain several chemical compounds, including alkaloids, saponins, amino acids, steroids, triterpenoids, phenolic compounds, and flavonoids [3].

Optimal wound healing could be achieved by paying greater attention to factors that could influence the continuity of the process. Arginine is one of the key factors since its metabolite, nitric oxide (NO), is required during the healing process. NO is produced through the action of endothelial NO synthase (eNOS) in endothelial cells with L-arginine as the substrate. When a wound occurs, arginine concentrations could decrease dramatically, affecting the amount of NO, and in turn, the healing process of the wound [4].

The presence of arginase, which would hydrolyze arginine to form ornithine and urea in the urea cycle, could also influence the amount of NO produced. However, since arginase is expressed at high levels in cells associated with wound healing processes, arginase would compete with eNOS to utilize arginine in the urea cycle [5]. Therefore, the use of arginase inhibitors could increase the amount of arginine available in the wound environment [6]. Several studies have reported that plant extracts that contain polyphenols such as flavonoids and resveratrol could inhibit the activity of arginase enzymes [7]. For example, Bordage et al. [7] demonstrated arginase activity inhibition by several plant compounds, including resveratrol, quercetin, chlorogenic acid, and epicatechin. In addition, according to Cray et al., [8] polyphenol compounds can act as chaotropic agents, which refer to compounds that can disrupt hydrogen bonds between water molecules. The results of the previous studies presented above suggest that there could be other compounds that could inhibit arginase, and such novel arginase inhibitors may be derived from plants [9].

\section{MATERIALS AND METHODS}

\section{Materials}

The roots of Sangketan were obtained from Klaten, Central Java, Indonesia. The chemicals and reagents used for extraction were sourced commercially. Arginase, L-arginine, maleic acid, and manganese sulfate were obtained from Sigma-Aldrich (Singapore); quercetin and gallic acid were obtained from Sigma-Aldrich (India); resveratrol was obtained from Wako (Japan); the urea kit assay was obtained from Abnova (Taiwan), while n-hexane, ethyl acetate, and methanol were obtained from Merck (Germany).

\section{Preparation of Sangketan root extracts}

\section{Extraction}

Dried Sangketan roots were ground into powder (500 g), which was then extracted using ultrasound-assisted extraction (UAE) and evaporated. As solvents, n-hexane, ethyl acetate, and methanol were sequentially used for the multistage extraction.

\section{Arginase activity inhibition test}

The inhibition test applied was a modified version of the tests outlined in the protocols published by Sigma-Aldrich (EC 3.5.3.2). The sample solution was made by mixing $10 \mu \mathrm{L}$ extract, $15 \mu \mathrm{L}$ arginase $1 \mathrm{U} / \mathrm{mL}$, and $20 \mu \mathrm{L}$-arginine substrate $380 \mathrm{mM}$. Subsequently, the sample solution was pre-incubated at $37^{\circ} \mathrm{C}$ for $30 \mathrm{~min}$. Immediately following the pre-incubation, $100 \mu \mathrm{L}$ urea assay reagent was added to the solution, which was then incubated at room temperature for an hour. The inhibition activity of arginase was determined on a microplate reader (Epoch, USA) [10]. Resveratrol was used as the positive control of arginase inhibition since resveratrol regularly found in plants and it could be at a higher rank with regard to inhibitory effects $\left(\mathrm{IC}_{50}\right)$ among other compounds such as epicatechin, quercetin, caffeic acid, kaempferol, and quinic acid [7]. 
Identification of phenol and flavonoid

The identification of phenol compounds and flavonoids was achieved using qualitative methods such as phytochemical screening and spraying of reagents on thin-layer chromatography plates.

For phenol identification, $3 \%$ iron trichloride $\left(\mathrm{FeCl}_{3}\right)$ solution was added to the sample solutions to observe whether the colors would change. For identification with spray reagents on the TLC plate, standard gallic acid dissolved in $96 \%$ ethanol was used as a reference. Silica gel 60 F254 was used as the stationary phase and chloroform-acetone-formic acid (9:3:1) was used as the mobile phase. After the plate was eluted, it was sprayed with $3 \% \mathrm{FeCl}_{3}$ solution.

For flavonoid identification, zinc powder, magnesium powder, and aluminum chloride $\left(\mathrm{AlCl}_{3}\right)$ spray reagent were used to observe the color changes on the sample solutions. For identification with spray reagents on the TLC plate, standard quercetin dissolved in $96 \%$ ethanol was used as a reference. Silica gel 60 F254 was used as the stationary phase and chloroform-acetone-formic acid (10:2:1) was used as the mobile phase. After the plate was eluted, it was sprayed with $5 \% \mathrm{AlCl}_{3}$ and then viewed under ultraviolet (UV) light (366 nm).

\section{Determination of total phenolic contents}

The determination of total phenol contents was performed on a microplate reader $[1,11]$. Sample solutions were prepared in $5000 \mu \mathrm{g} / \mathrm{mL}$. First, $20 \mu \mathrm{L}$ of sample solution was mixed with $100 \mu \mathrm{L}$ of the Folin-Ciocalteu reagent (1:4) and shaken for a minute in a 96-well microplate. The mixtures were left to stand for $2 \mathrm{~min}$ and then $75 \mu \mathrm{L}$ of sodium carbonate $\left(\mathrm{Na}_{2} \mathrm{CO}_{3}\right)$ solution $(100 \mathrm{~g} / \mathrm{mL})$ was added to the mixture and shaken for a minute. After being left to stand for $2 \mathrm{~h}$ at room temperature, the mixtures were measured using the microplate reader at $750 \mathrm{~nm}$ to obtain absorbance values. Blank solutions were measured without the addition of samples or standard solutions in the wells, which were replaced with methanol. Gallic acid was used as a standard, and $25,50,75,100,125$, and $150 \mu \mathrm{g} / \mathrm{mL}$ concentrations were prepared for the generation of a standard curve.

\section{Determination of total flavonoid content}

Total flavonoid contents were determined using a UV-visible spectrophotometer according to Indonesian Herbal Pharmacopoeia (Supplement III). Sample solutions were made in 4000-10,000 $\mu \mathrm{g} / \mathrm{mL}$. First, $0.5 \mathrm{~mL}$ sample solutions were prepared and then $1.5 \mathrm{~mL}$ of $96 \%$ ethanol, $0.1 \mathrm{~mL}$ of $\mathrm{AlCl}_{3}(10 \%), 0.1 \mathrm{~mL}$ sodium acetate $(100 \mathrm{~g} / \mathrm{mL})$, and $2.8 \mathrm{~mL}$ of distilled water were added to the samples. The mixtures were shaken and left to stand at room temperature for $30 \mathrm{~min}$. Afterward, the total flavonoid contents in the mixtures were measured using a UV-visible spectrophotometer at $415 \mathrm{~nm}$ to obtain the absorbance. Blank solutions were measured without the addition of $\mathrm{AlCl}_{3}(10 \%)$, which was replaced with distilled water. Quercetin was used as a standard, and 10, 20, 30, 40,50, and $60 \mu \mathrm{g} / \mathrm{mL}$ concentrations were prepared and use to generate a standard curve.

\section{RESULTS}

\section{Extraction}

The extract was produced by multistage UAE method uses n-hexane, ethyl acetate, and methanol solvents. The highest yield was produced from the extraction with methanol solvent (4.528\%) and the lowest one was produced from the extraction with ethyl acetate solvent (1.556\%).

\section{Arginase activity inhibition test}

The results of inhibitory activity percentage of each extract sorted from the highest are methanol extract $(29.7765 \%)$ followed by ethyl acetate extract (17.5818\%) and n-hexane extract (9.5617\%).

\section{Identification of phenolic and flavonoid compounds}

Each extract is identified which contains phenolic and flavonoid compounds except the $\mathrm{n}$-hexane extract that does not contain flavonoid compound.
Determination of total phenolic content

Methanol extract has the highest result of average phenol content (11.189 mg GAE/g sample) followed by ethyl acetate extract (4.830 mg GAE/g sample) and n-hexane extract (3.917 mg GAE/sample).

\section{Determination of total flavonoid content}

Related to the results of total phenolic content, methanol extract also has the highest average flavonoid content $(0.884 \mathrm{mg} Q \mathrm{E} / \mathrm{g}$ sample) followed by ethyl acetate extract ( $0.804 \mathrm{mg} \mathrm{QE} / \mathrm{g}$ sample) and n-hexane extract (0.296 mg QE/g sample).

\section{DISCUSSION}

Extraction is a separation process that separates the active compound from its matrix in plant tissues using a selective solvent. The multistage UAE method uses n-hexane, ethyl acetate, and methanol solvents, which dissolves compounds based on their polarities. The UAE method is facilitated by ultrasound, which can increase the permeability of a cell wall and form cavities that facilitate the release of bioactive compounds in Simplicia [12]. As shown in Table 1, the polar methanol solvent showed the highest yield, followed by n-hexane (non-polar solvent) and ethyl acetate (semi-polar solvent), in that order.

\section{Arginase activity inhibition test}

The arginase activity inhibition test was performed using a microplate reader based on a modified method of the Sigma-Aldrich enzyme test protocol, which measured the production of urea, which is the final product of the arginase reaction with L-arginine. Theoretically, the extract is considered to exhibit good enzyme inhibitory activity if it can inhibit $50 \%$ enzyme activity or more at a concentration of $\leq 100 \mu \mathrm{g} / \mathrm{mL}$. The results obtained using $100 \mu \mathrm{g} / \mathrm{mL}$ final concentration extracts (Table 2) showed that all the three extracts had low arginase inhibitory activity since they did not attain 50\% inhibitory activity.

\section{Identification of phenolic compounds and flavonoids}

As displayed in Table 3, the identification of the phenolic compounds in the n-hexane, ethyl acetate, and methanol extracts had positive results based on the $\mathrm{FeCl}_{3}$ reagent, which give rise to a blackish-green color after its addition. The presence of phenol groups is characterized by the formation of a dark green or dark blue color due to the formation of complex compounds following the addition of $\mathrm{Fe}^{3+}$. Identification was also carried out on the TLC plates using spray reagents. Gallic acid was

Table 1: Percentage yield of plant extracts in different solvents

\begin{tabular}{lllll}
\hline No. & Solvent & Simplicia weight (g) & Extract weight (g) & Yield (\%) \\
\hline 1. & n-Hexane & 300.07 & 7.42 & 2.472 \\
2. & $\begin{array}{l}\text { Ethyl } \\
\text { acetate }\end{array}$ & 300.07 & 4.67 & 1.556 \\
3. & Methanol & 300.07 & 13.59 & 4.528 \\
\hline
\end{tabular}

Table 2: Percentage inhibition of Sangketan extracts

\begin{tabular}{llll}
\hline Sample & \% inhibition & $\begin{array}{l}\text { Standard } \\
\text { deviation }\end{array}$ & $\begin{array}{l}\text { Coefficient of } \\
\text { variation (\%) }\end{array}$ \\
\hline n-Hexane extract & 9.5617 & 0.7355 & 7.6923 \\
Ethyl acetate extract & 17.5818 & 2.8440 & 12.4243 \\
Methanol extract & 29.7765 & 4.5250 & 15.1966 \\
\hline
\end{tabular}

Table 3: Identification of phenols and flavonoids in Sangketan extracts

\begin{tabular}{llll}
\hline $\begin{array}{l}\text { Chemical } \\
\text { content }\end{array}$ & $\begin{array}{l}\text { n-Hexane } \\
\text { extract }\end{array}$ & $\begin{array}{l}\text { Ethyl acetate } \\
\text { extract }\end{array}$ & $\begin{array}{l}\text { Methanol } \\
\text { extract }\end{array}$ \\
\hline Phenols & + & + & + \\
Flavonoids & - & + & + \\
\hline
\end{tabular}


used as a standard and all three extracts were applied as spots on the TLC plate, which we then eluted using chloroform-acetone-formic acid (9:3:1), as the mobile phase. After the elution process was complete, the plate was sprayed $\mathrm{FeCl}_{3}$. The results were observed in the form of visible spots on the gallic acid positive control and methanol extract with similar retention factor $\left(\mathrm{R}_{\mathrm{f}}\right)$

Identification of flavonoid on the n-hexane, ethyl acetate, and methanol extracts revealed different results (Table 3 ). The results were negative for the n-hexane extract and positive for the ethyl acetate and methanol extracts. The results were considered positive if orange or red colors were present in the reaction using magnesium powder with hydrochloric acid and zinc powder with hydrochloric acid. The magnesium and zinc with the hydrochloric acid in the test would initiate a reaction that would reduce the benzopyrone nuclei in the flavonoid structure, which would result in color change from orange or red. The test would also be considered positive when yellow fluorescence was observed under UV light at $366 \mathrm{~nm}$ after the spraying of $\mathrm{AlCl}_{3}$. In addition, quercetin was used as a standard and the three extracts were also applied on the TLC plate as spots and then eluted using the chloroform-acetone-formic acid (10:2:1) mobile phase. When the elution process was complete, the plate was sprayed with $\mathrm{AlCl}_{3}$. There were fluorescent spots on the plates when the quercetin solution, n-hexane extract, ethyl acetate extract, and methanol extracts with similar $\mathrm{R}_{\mathrm{f}}$ were viewed under UV light at $366 \mathrm{~nm}$.

Based on the results of the previous enzyme tests, identification results for phenolic and flavonoid compounds imply that they may play a role in arginase inhibition. However, other compounds in the extracts could have played a role in the results observed.

\section{Determination of total phenolic content}

The determination of total phenol content was carried out using the Folin-Ciocalteu reagent with a microplate reader. The underlying principle of the reaction that occurs between the Folin-Ciocalteu reagent and phenolic compounds in the sample is an oxidation reaction and colorimetric reduction. The phosphomolybdate-phosphotungstate compounds in the Folin-Ciocalteu reagent will be reduced by hydroxyl groups in phenolic compounds to form a blue molybdenum-tungsten complex [13]. The aim of adding $\mathrm{Na}_{2} \mathrm{CO}_{3}$ solution was to produce an alkaline environment. The alkaline environment was required because a colorimetric reduction reaction can only take place in an alkaline environment. The intensity of the blue color formed corresponded to the amount of phenolic compounds in the sample. The more intense the blue color, the higher the phenolic compound content. The determination process was initiated by generating a standard gallic acid calibration curve. The linear regression equation that resulted was used to calculate the total phenol compound contents in the samples. Measurements were performed using a microplate reader at a wavelength of $750 \mathrm{~nm}$ [14]. The linear regression equation was $y=0.0068 x-0.0069(r=0.99985)$.

The average total phenol content was obtained by substituting the absorbance value of the extract into the linear regression equation presented in Table 4 . If the percentage enzyme inhibitory activity corresponded to the concentrations determined using the linear regression equation, then the result of total phenolic content would be considered to be correlated. The n-hexane extract sample with the least inhibition value also had the lowest amount of total phenol content, while methanol extract sample with the highest inhibition value had the highest total phenol content. Several previous studies have revealed that the compounds that can inhibit arginase enzyme activity are generally classified as flavonoids, where flavonoids are derivatives of the phenol group. Therefore, the high phenolic content in a sample may indicate high flavonoid contents in the samples $[13,15]$.

\section{Determination of total flavonoid content}

Total flavonoid contents were determined using the colorimetric method using UV-visible spectrophotometry with $\mathrm{AlCl}_{3}$ and sodium
Table 4: Total phenolic content of Sangketan extracts

\begin{tabular}{lll}
\hline Sample & Absorbance & $\begin{array}{l}\text { Average phenol content } \\
\text { (mg GAE/g sample) }\end{array}$ \\
\hline n-Hexane extract & 0.345 & 3.917 \\
& 0.349 & \\
Ethyl acetate extract & 0.337 & \\
& 0.482 & 4.830 \\
& 0.470 & \\
Methanol extract & 0.466 & \multirow{2}{*}{11.189} \\
& 1.039 & \\
& 1.041 & \\
\hline
\end{tabular}

Table 5: Total flavonoid content of Sangketan extracts

\begin{tabular}{lll}
\hline Sample & Absorbance & $\begin{array}{l}\text { Average flavonoid content } \\
\text { (mg QE/g sample) }\end{array}$ \\
\hline n-Hexane extract & 0.431 & 0.296 \\
& 0.437 & \\
Ethyl acetate extract & 0.438 & \\
& 0.596 & 0.804 \\
Methanol extract & 0.589 & \\
& 0.580 & \\
& 0.513 & 0.884 \\
& 0.475 & \\
\hline
\end{tabular}

acetate reagents. The results were expressed as milligram of quercetin equivalent/g sample. Quercetin was selected as a standard because it is classified as a flavonoid in flavonol group, which has a keto group on the C-4 atom and a hydroxyl group on the C-3 and C-5 atoms. The underlying principle of the above method of the determination of total flavonoid content using $\mathrm{AlCl}_{3}$ reagent is the formation of acid-resistant complexes between aluminum ions with C-4 keto groups and C-3 or C-5 hydroxyl groups in flavonoids, resulting in the formation of a yellow color. The addition of sodium acetate can detect the presence of free 7-hydroxyl groups in flavones and flavonols.

We first prepared a standard quercetin calibration curve. The linear regression equation that resulted was used to calculate the total flavonoid contents in the samples. Measurements were obtained using UV-visible spectrophotometry at $430 \mathrm{~nm}$, which is the wavelength that displays maximum absorption. The linear regression equation was $y=0.0076 x+0.1327(r=0.99905)$. The average total flavonoid contents were obtained by substituting the absorbance values of the extracts into the linear regression equation (Table 5). Similar to the results of total phenolic content, when the results of total flavonoid contents corresponded to the enzyme inhibitory activity values, it suggested correlation. The n-hexane extract with the least inhibition value had the lowest total flavonoid levels, while the methanol extract with the highest inhibition value, the highest the total flavonoid levels. Based on the previous studies, some of the compounds that inhibit the arginase enzyme activity have been classified as flavonoids.

\section{CONCLUSION}

The roots extract of Sangketan had low potency of arginase inhibitory activity. Based on the previous enzyme tests, identification results for phenolic and flavonoid compounds imply that they may play a role in arginase inhibition. Thus, further studies are suggested to investigate other compounds in the extracts, which it could have played a role in the results observed.

\section{ACKNOWLEDGMENTS}

This work was supported by University of Indonesia through Doctoral Grant 2018. 


\section{CONFLICTS OF INTEREST}

There are no conflicts of interest.

\section{REFERENCES}

1. Pandey NK, Sharma HP, Amit P, Paras J. A review on potential magic folk herbal medicinal plant: Achyranthes aspera L. Int J Med Plants Photon 2013;105:350-63.

2. Kamalakkannan K, Balakrishnan B. Studies on the effect of antidiabetic activity of Achyranthes aspera L. On alloxan induced wistar rats. Int J Pharm Pharm Sci 2015;7:61-4.

3. Bhosale UA, Yegnanarayan R, Pophale P, Somani R. Effect of aqueous extracts of Achyranthes aspera Linn. On experimental animal model for inflammation. Anc Sci Life 2012;31:202-6.

4. Gould A, Naidoo C, Candy GP. Arginine Metabolism and Wound Healing. Vol. 1. Pune: WHSA; 2008. p. 48-50.

5. Steppan J, Nyhan D, Berkowitz DE. Development of novel arginase inhibitors for therapy of endothelial dysfunction. Front Immunol 2013;4:278

6. Kavalukas SL, Uzgare AR, Bivalacqua TJ, Barbul A. Arginase inhibition promotes wound healing in mice. Surgery 2012;151:287-95.

7. Bordage S, Pham TN, Zedet A, Gugglielmetti AS, Nappey M, Demougeot $\mathrm{C}$, et al. Investigation of mammal arginase inhibitory properties of natural ubiquitous polyphenols by using an optimized colorimetric microplate assay. Planta Med 2017;83:647-53

8. Cray JA, Bhaganna P, Singhal RS, Patil SV, Saha D, Chakraborty R, et al.
Chaotropic and hydrophobic stress mechanism of antifungal substances. In: Dehne HW, Deising HB, Fraaije B, Gisi U, Hermann D, Mehl A, et al., editors. Modern Fungicides and Antifungal Compounds. Vol. 7. Braunschweig: Deutsche Phytomedizinische Gesellschaft; 2014. p. 73-80.

9. Girard-Thernier C, Pham TN, Demougeot C. The promise of plantderived substances as inhibitors of arginase. Mini Rev Med Chem 2015;15:798-808

10. Zalsabela TL, Elya B, Noviani A. Arginase inhibition activity of stem bark extract of Caesalpinia pulcherrima. J Young Pharm 2018;10:111-3.

11. Bobo-García G, Davidov-Pardo G, Arroqui C, Vírseda P, MarínArroyo MR, Navarro M. Intra-laboratory validation of microplate methods for total phenolic content and antioxidant activity on polyphenolic extracts, and comparison with conventional spectrophotometric methods. J Sci Food Agric 2015;95:204-9.

12. Medina-Torres N, Ayora-Talavera T, Espinosa-Andrews H, SánchezContreras A, Pacheco N. Ultrasound assisted extraction for the recovery of phenolic compounds from vegetable sources. Agronomy 2017;7:47.

13. Adawiah A, Sukandar D, Muawanah A. Antioxidant activity and content of bioactive components of namnam juice. J Kimia Valensi 2015;1:130-6.

14. Ministry of Health of the Republic of Indonesia. Indonesian Herbal Pharmacopoeia (Supplement III). Vol. 1. Jakarta: Ministry of Health of the Republic of Indonesia; 2013.

15. Singh H, Dixit A, Sharma RA, Sharma A. Comparative evaluation of total phenolic content, total flavonoid content and dpph free radical scavenging activity of different plant parts of Vitex negundo L. Int $\mathrm{J}$ Pharm Pharm Sci 2014;7:144-7. 